\title{
Refractory rickets caused by mild distal renal tubular acidosis
}

\author{
Ji-Ho Lee, MD, \\ Joo Hyun Park, MD, \\ Tae-Sun Ha, MD, \\ Heon-Seok Han, MD \\ Department of Pediatrics, \\ Chungbuk National University \\ College of Medicine, Cheongju, \\ Korea
}

Type I (distal) renal tubular acidosis (RTA) is a disorder associated with the failure to excrete hydrogen ions from the distal renal tubule. It is characterized by hyperchloremic metabolic acidosis, an abnormal increase in urine $\mathrm{pH}$, reduced urinary excretion of ammonium and bicarbonate ions, and mild deterioration in renal function. Hypercalciuria is common in distal RTA because of bone resorption, which increases as a buffer against metabolic acidosis. This can result in intractable rickets. We describe a case of distal RTA with nephrocalcinosis during follow-up of rickets in a patient who presented with clinical manifestations of short stature, failure to thrive, recurrent vomiting, dehydration, and irritability.

Keywords: Distal renal tubular acidosis, Rickets, Nephrocalcinosis

\section{Introduction}

Rickets is a disease of growing bone that is due to unmineralized matrix at the growth plates $^{1)}$. Vitamin D deficiency is the most common cause of rickets ${ }^{2,3)}$, but any condition that disturbs bone mineralization, including distal renal tubular acidosis (RTA), can cause rickets ${ }^{4,5}$. Distal RTA is commonly accompanied by hypercalciuria and nephrocalcinosis, resulting in calcium deficiency ${ }^{6}$.

Distal RTA is a disease of defective urinary acidification, which is caused by insufficient net acid excretion by the kidneys ${ }^{7)}$. The disease is characterized by alkaline urine in the presence of systemic metabolic acidosis. In its severe form, affected patients are very acidotic and volumedepleted, with marked hypokalemia but otherwise normal renal excretory function. Levels of calcium and phosphate are usually normal, but growth is poor, and rickets is common in untreated cases because of leaching of minerals from the bones in an attempt to buffer the acidosis. Bone resorption by osteoclasts is increased in acidosis ${ }^{8)}$.

We describe a case of distal type RTA with renal calcification in children during follow-up of a rickets patient who presented with clinical manifestations of short stature, failure to thrive, recurrent vomiting, dehydration, and irritability.

\section{Case report}

A 6-year-old boy was hospitalized because of delayed speech, failure to thrive, and weakness in both legs. He was born at 32+0 weeks' gestation by cesarean section and weighed $1.8 \mathrm{~kg}$. He was slow to gain weight and had constipation since he was 6 months old. At 4 years of age, he could not walk very well, and both legs were thin on presentation. He had two elder sisters and one elder brother, and no one had experienced similar problems.

His vital signs were unremarkable. He was short in stature, measuring $95 \mathrm{~cm}(<3 \mathrm{rd}$ percentile) and weighing $15.6 \mathrm{~kg}(<3 \mathrm{rd}$ percentile). A complete blood cell count was normal. Electrolyte battery showed hypokalemia and hyperchloremia. Serum calcium was within the normal range, serum phosphate was decreased, and alkaline phosphatase was markedly

\author{
Address for correspondence: \\ Heon Seok Han, MD \\ Chungbuk National University \\ College of Medicine, 410 \\ Sunbong-ro, Heungdeok-gu, \\ Cheongju 361-763, Korea \\ Tel: $+82-43-269-6370$ \\ Fax: +82-43-264-6620 \\ E-mail:hshan@chungbuk.ac.kr
}

This is an Open Access article distributed under the terms of the Creative Commons Attribution Non-Commercial License (http:// creativecommons.org/licenses/by-nc/3.0) which permits unrestricted non-commercial use, distribution, and reproduction in any medium, provided the original work is properly cited. 
increased. Arterial blood gas analysis showed mild metabolic acidosis, with a normal anion gap (Table 1). Urine electrolytes showed decreased chloride excretion, with a positive urine anion gap and marked hypercalciuria in 24-hour urine. Thyroid function tests were normal. Levels of 25-hydroxy $(25-\mathrm{OH})$ vitamin $\mathrm{D}$ and 1,25-dihydroxy $(1,25-\mathrm{OH})$ vitamin $\mathrm{D}$ were decreased. Parathyroid hormone levels were within the normal range. A skeletal survey showed diffuse osteopenia, fraying in the distal radius and fracture of the left tibia and both fibulae (Fig. 1). Lumbar bone mineral density was decreased in dual energy X-ray absorptiometry (DEXA). A brain magnetic resonance imaging was normal. Brainstem auditory evoked potential showed no significant sensorineural hearing loss, with a threshold of $20 \mathrm{~dB}$ bilaterally. Electromyography and nerve conducting velocity showed no unequivocal electrophysiological abnormalities.

He was managed with oral calcium, vitamin D, and spironolactone, with intravenous potassium chloride replacement. After a few days, his hypokalemia and metabolic acidosis were corrected, and he was discharged.

At 11 years of age, he was hospitalized again because of vomi-ting, irritability, and poor oral intake. Despite long-term

Table 1. Laboratory findings at two different time points

\begin{tabular}{|c|c|c|}
\hline Laboratory finding & $\begin{array}{c}\text { Age of } 6 \\
\text { (at the time of } \\
\text { diagnosis) }\end{array}$ & $\begin{array}{c}\text { Age of } 11 \\
\text { (after treatment) }\end{array}$ \\
\hline \multicolumn{3}{|l|}{ Serum } \\
\hline Sodium (mEq/L) & 139 & 148 \\
\hline Potassium (mEq/L) & 2.1 & 1.7 \\
\hline Chloride (mEq/L) & 114 & 121 \\
\hline Total $\mathrm{CO}_{2}(\mathrm{mEq} / \mathrm{L})$ & 10 & 9 \\
\hline Calcium (mg/dL) & 8.6 & 6.8 \\
\hline Phosphorus (mg/dL) & 1.4 & 0.9 \\
\hline Alkaline phosphatase (IU/L) & 3,408 & 1,864 \\
\hline Arterial blood pH & 7.34 & 7.25 \\
\hline \multicolumn{3}{|l|}{ Spot urine } \\
\hline $\mathrm{pH}$ & 7.5 & 6.5 \\
\hline Sodium (mEq/L) & 37 & 13 \\
\hline Potassium (mEq/L) & 10.4 & 11.4 \\
\hline Chloride (mEq/L) & 35 & 15 \\
\hline Anion gap (mEq/L) & 12.4 & 9.4 \\
\hline \multicolumn{3}{|l|}{ 24-hr urine } \\
\hline Sodium (mEq/day) & 45 & 99 \\
\hline Potassium (mEq/day) & 29.5 & 83.2 \\
\hline Chloride (mEq/day) & 57 & 109 \\
\hline Calcium (mg/day) & 103.9 & 88.0 \\
\hline Creatinine (mg/day) & 100 & 260 \\
\hline $\mathrm{Ca} / \mathrm{Cr}$ ratio & 1.039 & 0.338 \\
\hline \multicolumn{3}{|l|}{ Hormone } \\
\hline 25-OH Vitamin D (ng/mL) & 13.60 & 31.58 \\
\hline Parathyroid hormone (pg/mL) & 28.8 & 14.3 \\
\hline \multicolumn{3}{|l|}{ Bone densitiometry } \\
\hline BMD at L1-4 $\left(\mathrm{g} / \mathrm{cm}^{2}\right)$ & 0.107 & 0.419 \\
\hline
\end{tabular}

25-OH, 25-hydroxy; BMD, bone mineral density; L, lumbar. calcium, potassium, and vitamin D therapy, he was still short in stature. He measured $110 \mathrm{~cm}(<3$ rd percentile) and weighed $32 \mathrm{~kg}$ (25th to 50th percentile). Electrolyte battery showed hypokalemia and hyperchloremia. Chemical batteries showed hypocalcemia and hypophosphatemia, and alkaline phosphatase was still increased. Arterial blood gas analysis showed metabolic acidosis with a normal anion gap (Table 1). Urinalysis showed alkaline urine indicative of metabolic acidosis, with a positive urine anion gap. A 24-hour urine analysis showed improved but persistent hypercalciuria. Levels of $25-\mathrm{OH}$ vitamin $\mathrm{D}$ and 1,25-OH vitamin $\mathrm{D}$ were within the normal range. A skeletal survey showed persistent diffuse osteopenia, fraying in both the distal radius and the ulna and fracture of the left tibia and fibula (Fig. 1). The lumbar bone mineral density was still decreased in DEXA but increased compared with the previous study. Kidney ultrasonography showed increased echogenecity in renal parenchyma bilaterally (Fig. 2), but a 99mTc-dimercaptosuccinic acid renal scan was normal, and there was no evidence of decreased excretory function. Abdomen and pelvis computerized tomography showed multiple calcified nodules in both renal parenchymae and thinning of the renal cortex (Fig. 3).

He was managed for distal RTA with fluid therapy and a large amount of bicarbonate $(5-10 \mathrm{mEq} / \mathrm{kg} /$ day $)$ and potassium

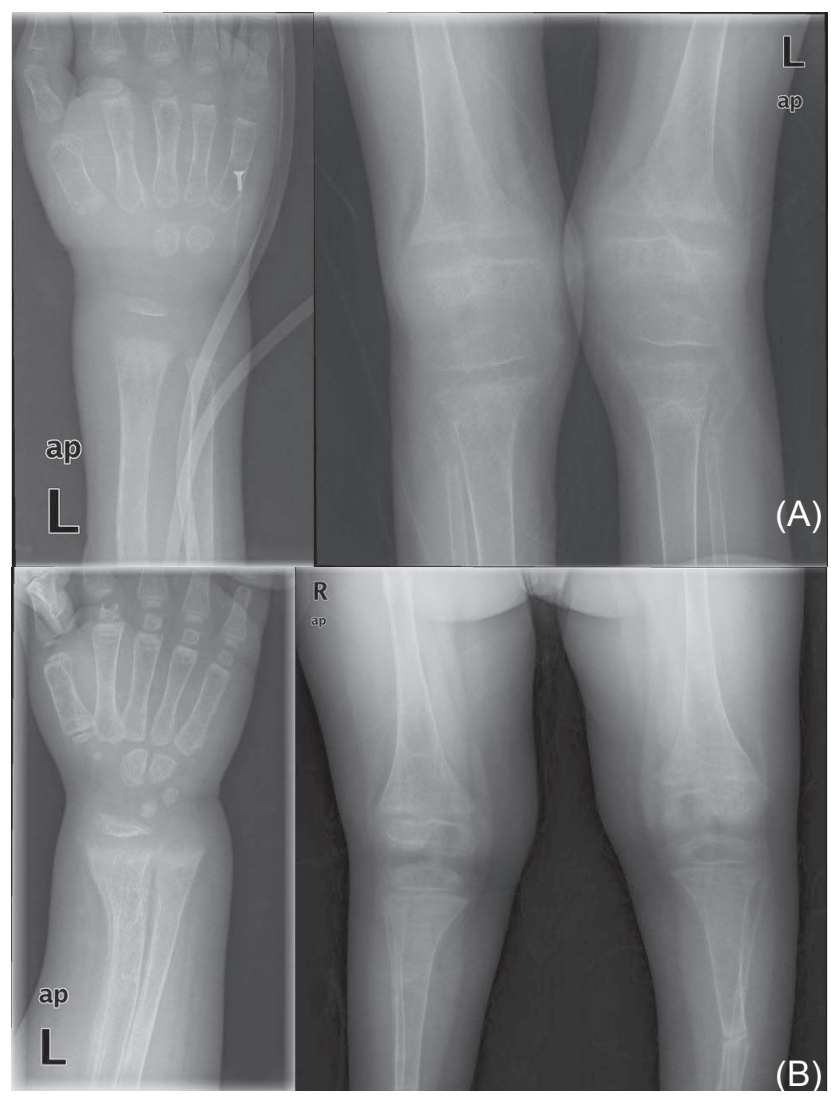

Fig. 1. Skeletal X-ray at two different time points. (A) At the age of 6 years, showing diffuse osteopenia, fraying in the both distal radius and ulna, with fracture of the left tibia and both fibula. (B) At the age of 11 years, showing diffuse osteopenia, fraying of the distal radius and ulna, with fracture of the left tibia and fibula. 


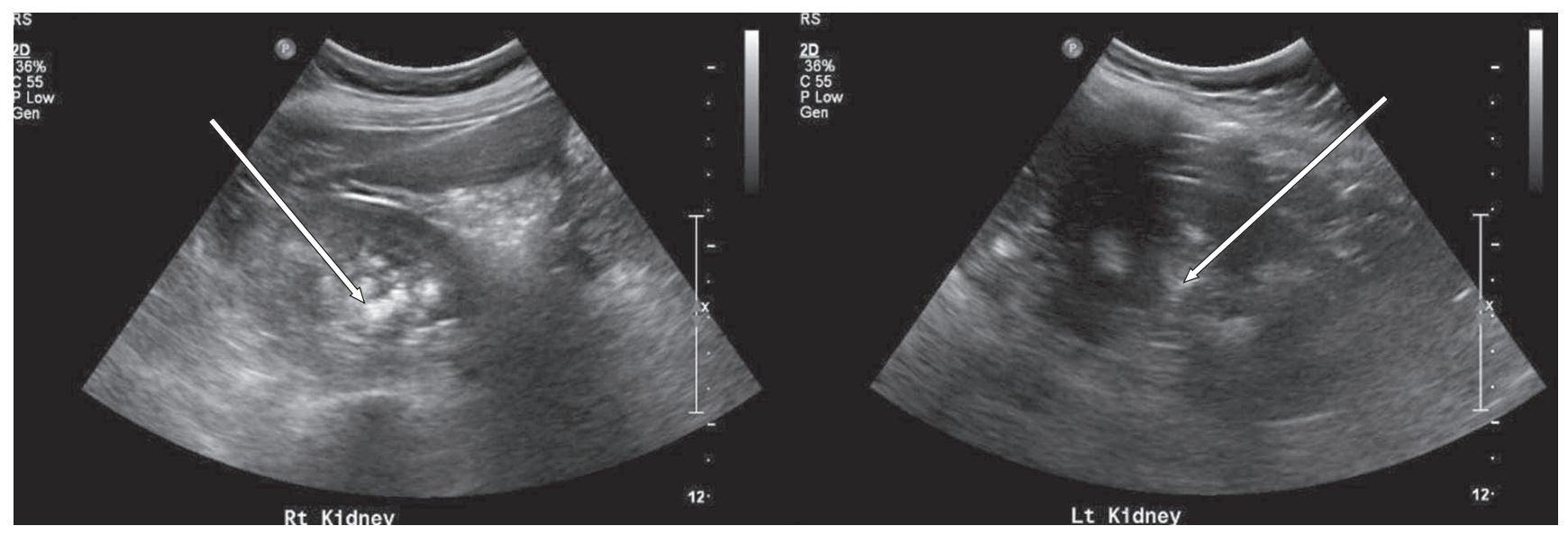

Fig. 2. Ultrasonography showing increased echogenecity and nephrocalcinosis in the renal parenchyma of both kidneys.
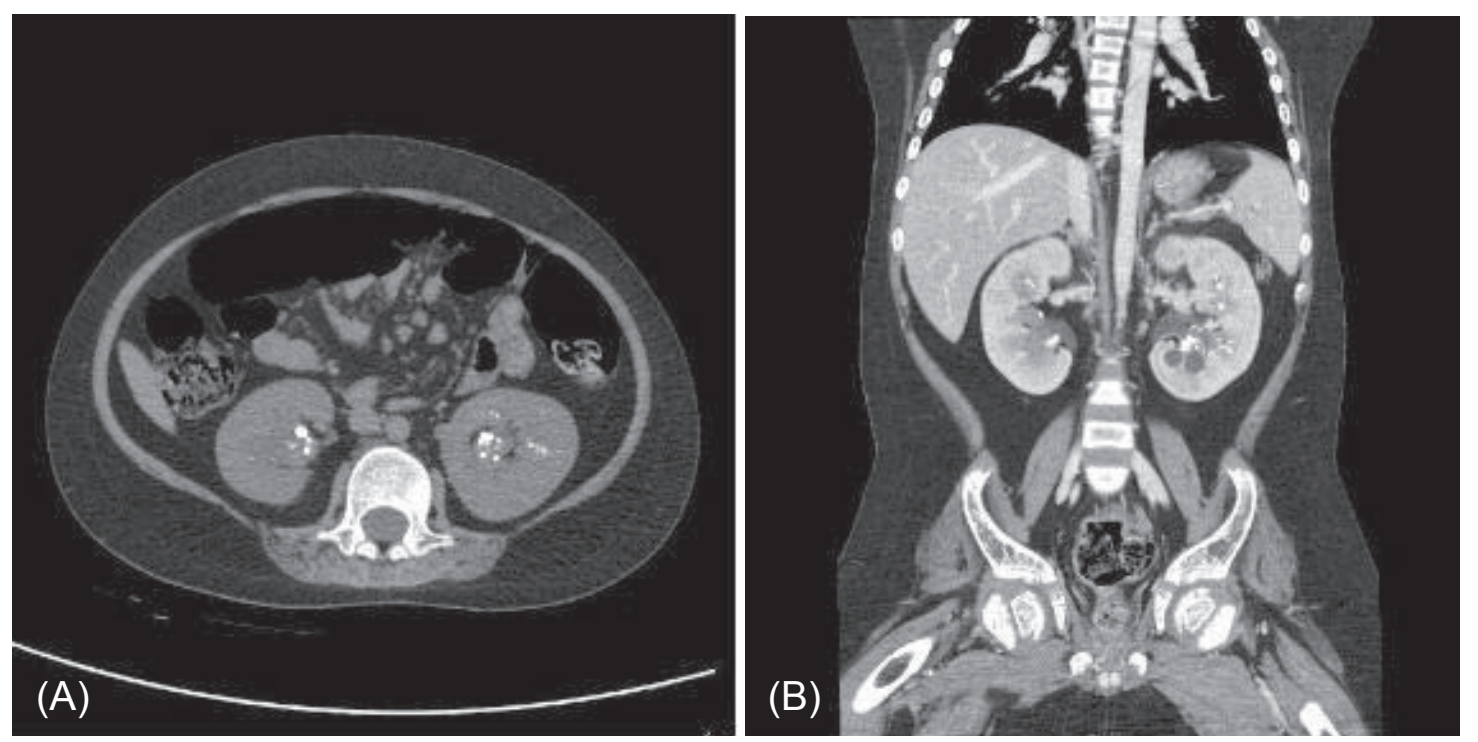

Fig. 3. Abdomen and pelvis CT showing multiple calcified lesions in both kidneys. (A) A precontrast axial image showing multiple calcified lesions in both renal parenchyma. (B) A postcontrast coronal image showing multiple calcified lesions in both renal parenchyma and simple cysts in left kidney.

citrate $(5 \mathrm{mEq} / \mathrm{kg} / \mathrm{day})$. Dehydration and acidosis were completely corrected. He started to gain weight two weeks after the commencement of the therapy, and his electrolyte levels returned to normal. Hypercalciuria was improved, but the calcium/creatinine ratio was still high. The patient is now 12 years old. He is still of short stature and shows rachitic changes.

\section{Discussion}

RTA is a clinical syndrome that causes hyperchloremic metabolic acidosis due to a disorder of urine acidification. The acidification of urine in the distal tubule primarily depends on acid-base exchange transporters in intercalated cells. There are three related processes: provision of $\mathrm{H}^{+}$and $\mathrm{HCO}_{3}{ }^{-}$ions from $\mathrm{H}_{2} \mathrm{O}$ and $\mathrm{CO}_{2}$ by cytosolic carbonic anhydrase II (CA II), excretion of $\mathrm{H}^{+}$ions into the collecting tubule by vacuolar
$\mathrm{H}^{+}$-ATPase, and excretion of $\mathrm{HCO}_{3}{ }^{-}$ions into the blood by the $\mathrm{HCO}_{3}{ }^{-} / \mathrm{Cl}^{-}$anion exchanger $(\mathrm{AE} 1)^{9}$. Impaired function of any of these components can cause a defect in urine acidifica-tion, and the severity of functional defect depends on the importance of affected component ${ }^{10)}$. Genetic mutations causing functionional impairment of the components were recently discovered, with studies reporting that mutations in the gene encoding cytosolic CA II are associated with mixed-type distal and proximal RTA and with cerebral calcification ${ }^{11,12)}$. Mutations in the gene that encodes AE1 usually result in distal $\mathrm{RTA}^{13)}$. Mutations in the ATP6VOA4 and ATP6V1B1 genes encoding the a 4 and B1 subunits of vacuolar $\mathrm{H}^{+}$-ATPase can cause inherited distal RTA and sensorineural hearing loss ${ }^{14-16)}$. Most patients with distal RTA have hypokalemia because the inability to excrete $\mathrm{H}^{+}$is compensated for by increased $\mathrm{K}^{+}$secretion.

In this case, the patient had chronic hyperchloremic metabolic 
acidosis, a normal anion gap, alkaline urine with a positive urine anion gap, hypokalemia, and nephrocalcinosis. Although these findings are consistent with distal RTA, there was no evidence of sensorineural hearing loss or cerebral calcification. A mutation of AE1 was suspected, but we did not perform a genetic study to identify the mutations accompanying the RTA. The current case also appears to be incomplete distal RTA $^{17)}$ because the

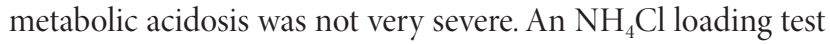
would be required to confirm the diagnosis, but we did not perform it. This could be a limitation of our study.

The aim of distal RTA treatment in children is not only correcting biochemical abnormalities, but also improving growth and preventing kidney stones and skeletal abnormalities. The basis of the treatment is alkali replacement. Potassium citrate or sodium citrate is preferable to bicarbonate because citrate salt can correct hypocitraturia and prevent nephrolithiasis. Potassium supplementation and $\mathrm{K}^{+}$-sparing diuretics, such as spironolactone or amiloride, are necessary to manage the hypokalemia. If the distal RTA is accompanied by rickets, calcium, and vitamin D replacement are required. In this case, despite treatment, the patient's vertical growth and bone mineral density remained poor. His short stature may be due to another cause or due to insufficiency of the treatment. Some reports have described delayed bone age and decreased growth velocity in distal RTA $^{18)}$. Phosphate supplementation could improve clinical features in vitamin D-resistant rickets with $\mathrm{RTA}^{19)}$. So, in cases that fail to respond to calcium and vitamin D replacement therapy, further tests should be conducted to determine the source of the short stature. And if needed, treatment with growth hormones and bisphosphonate should be considered ${ }^{20)}$.

\section{Conflict of interest}

No potential conflict of interest relevant to this article was reported.

\section{References}

1. Hochberg Z. Rickets: past and present. Introduction. Endocr Dev 2003;6:1-13.

2. Pettifor JM. Rickets and vitamin D deficiency in children and adolescents. Endocrinol Metab Clin North Am 2005; 34:537-53, vii.

3. Holick MF. Vitamin D deficiency. N Engl J Med 2007;357: 266-81.

4. Kooh SW, Fraser D, Reilly BJ, Hamilton JR, Gall DG, Bell L. Rickets due to calcium deficiency. N Engl J Med 1977;297:1264-6.

5. Albright F, Burnett CH, Parson W, Reifenstein EC, Roos A. Osteomalacia and late rickets: Various etiologies met on United States with emphasis on that resulting from specific forms of renal acidosis, therapeutic implications for each etiological subgroup, and relationship between osteomalacia and Milkman's syndrome. Medicine
1946;25:399-479.

6. Rodriguez-Soriano J, Vallo A. Renal tubular acidosis. Pediatr Nephrol 1990;4:268-75.

7. Nicoletta JA, Schwartz GJ. Distal renal tubular acidosis. Curr Opin Pediatr 2004;16:194-8.

8. Lemann J Jr, Litzow JR, Lennon EJ. The effects of chronic acid loads in normal man: further evidence for the participation of bone mineral in the defense against chronic metabolic acidosis. J Clin Invest 1966;45:1608-14.

9. Rodriguez Soriano J. Renal tubular acidosis: the clinical entity. J Am Soc Nephrol 2002;13:2160-70.

10. Batlle D, Haque SK. Genetic causes and mechanisms of distal renal tubular acidosis. 2012;27:3691-704.

11. Borthwick KJ, Kandemir N, Topaloglu R, Kornak U, Bakkaloglu A, Yordam N, et al. A phenocopy of CAII deficiency: a novel genetic explanation for inherited infantile osteopetrosis with distal renal tubular acidosis. J Med Genet 2003;40:115-21.

12. Sly WS, Hewett-Emmett D, Whyte MP, Yu YS, Tashian RE. Carbonic anhydrase II deficiency identified as the primary defect in the autosomal recessive syndrome of osteopetrosis with renal tubular acidosis and cerebral calcification. Proc Natl Acad Sci U S A 1983;80:2752-6.

13. Bruce LJ, Cope DL, Jones GK, Schofield AE, Burley M, Povey S, et al. Familial distal renal tubular acidosis is associated with mutations in the red cell anion exchanger (Band 3, AE1) gene. J Clin Invest 1997;100:1693-707.

14. Stover EH, Borthwick KJ, Bavalia C, Eady N, Fritz DM, Rungroj N, et al. Novel ATP6V1B1 and ATP6V0A4 mutations in autosomal recessive distal renal tubular acidosis with new evidence for hearing loss. J Med Genet 2002;39:796-803.

15. Smith AN, Skaug J, Choate KA, Nayir A, Bakkaloglu A, Ozen S, et al. Mutations in ATP6N1B, encoding a new kidney vacuolar proton pump 116-kD subunit, cause recessive distal renal tubular acidosis with preserved hearing. Nat Genet 2000;26:71-5.

16. Karet FE, Finberg KE, Nelson RD, Nayir A, Mocan H, Sanjad SA, et al. Mutations in the gene encoding B1 subunit of H+-ATPase cause renal tubular acidosis with sensorineural deafness. Nat Genet 1999;21:84-90.

17. Oduwole AO, Giwa OS, Arogundade RA. Relationship between rickets and incomplete distal renal tubular acidosis in children. Ital J Pediatr 2010;36:54.

18. Chang CY, Lin CY. Failure to thrive in children with primary distal type renal tubular acidosis. Acta Paediatr Taiwan 2002;43:334-9.

19. Minari M, Castellani A, Garella S. Renal tubular acidosis associated with vitamin D-resistant rickets. Role of phosphate depletion. Miner Electrolyte Metab 1984;10:3714.

20. Hou JW. Amelioration of hypophosphatemic rickets and osteoporosis with pamidronate and growth hormone in Lowe syndrome. J Formos Med Assoc 2009;108:730-5. 